\title{
Tests of adrenal insufficiency
}

\author{
J C Agwu, H Spoudeas, P C Hindmarsh, P J Pringle, C G D Brook
}

\begin{abstract}
Aim-In suspected adrenal insufficiency, the ideal test for assessing the hypothalamo-pituitary-adrenal axis is controversial. Therefore, three tests were compared in patients presenting with symptoms suggestive of adrenal insufficiency.

Method-Responses to the standard short Synacthen test (SSST), the low dose Synacthen test (LDST), and the 08:00 hour serum cortisol concentration were measured in 32 patients. A normal response to the synacthen test was defined as a peak serum cortisol of $\geqslant 500 \mathrm{nmol} / 1$ and/or incremental concentration of $\geqslant 200 \mathrm{nmol} / 1$. The sensitivity and specificity of the 08:00 hour serum cortisol concentration compared with other tests was calculated.
\end{abstract}

Results-Three patients had neither an adequate peak nor increment after the SSST and LDST. All had a serum 08:00 hour cortisol concentration of $<200 \mathrm{nmol} / 1$. Eight patients had abnormal responses by both criteria to the LDST but had normal responses to the SSST. Three reported amelioration of their symptoms on hydrocortisone replacement. Twenty one patients had a normal response to both tests (of these, 14 achieved adequate peak and increment after both tests and seven did not have an adequate peak after the LDST but had a normal increment). The lowest 08:00 hour serum cortisol concentration above which patients achieved normal responses to both the LDST and SSST was $500 \mathrm{nmol} / 1$. At this cut off value (compared with the LDST), the serum 08:00 hour cortisol concentration had a sensitivity of $100 \%$ but specificity was only $33 \%$.

The London Centre for Paediatric

Endocrinology and Metabolism, Cobbold Laboratories, The Middlesex Hospital, Mortimer Street, London, WIN 8AA, UK H Spoudeas

P C Hindmarsh

P J Pringle

C G D Brook

Sandwell NHS Trust, Hallam Road, West

Bromich, West

Midlands, B71 4HJ, UK

J C Agwu

Correspondence to:

Professor Brook.

Accepted 3 November 1998

limited.

(Arch Dis Child 1999;80:330-333)

Keywords: Synacthen; adrenal insufficiency; hypothalamo-pituitary-adrenal axis

Many symptoms of adrenal insufficiency such as anorexia, weight loss, and fatigue are non-specific. In patients with suspected adrenal insufficiency, it is important that a diagnosis is made quickly to avoid the risk of developing acute adrenal crisis. There are many tests of hypothalamo-pituitary-adrenal function, but there is some controversy over which is the best.
Plasma cortisol secretion follows a circadian pattern with the highest concentrations being seen in the morning. A single estimation of the 08:00 hour serum cortisol concentration reflects endogenous activity of the hypothalamo-pituitary-adrenal axis. ${ }^{1}$ However, it is uncertain what cut off values should be used. ${ }^{2-5}$

The cortisol response to insulin induced hypoglycaemia has been validated against the response to surgical stress and is one of the most valuable tests of adrenal insufficiency. Unfortunately, it is both unpleasant and potentially dangerous ${ }^{6}$ and there remains a need for a simple, safe, and reliable screening test.

The standard short Synacthen test (SSST), in which a pharmacological dose of adrenocorticotrophic hormone (ACTH; $250 \mu \mathrm{g}$ / $1.73 \mathrm{~m}^{2}$ ) is given intravenously, directly measures adrenal reserve. It is also thought to assess hypothalamo-pituitary function indirectly, because chronic ACTH deficiency leads to a quiescent adrenal gland and therefore to an inadequate cortisol response to exogenous ACTH. The peak serum cortisol concentration obtained 30 minutes after the SSST has been shown to correlate with that obtained after insulin induced hypoglycaemia. ${ }^{78}$ Some patients with normal responses to the SSST have been shown later to have adrenal insufficiency. ${ }^{910}$ The lowest dose of ACTH capable of eliciting a maximum response of cortisol in healthy children and adults is $500 \mathrm{ng} / 1.73 \mathrm{~m}^{2} .{ }^{11}{ }^{12}$ This dose of ACTH, which is 500 times less than that used in the standard test, leads to a rise in serum cortisol concentration over the first 20 minutes identical to that obtained after injection of the standard dose, ${ }^{12-14}$ and is the dose used in the low dose synacthen test (LDST). The LDST may provide a more sensitive test of adrenal function.

We assessed the 08:00 hour serum cortisol concentration and responses to the LDST and SSST in 32 patients presenting with symptoms suggestive of adrenal insufficiency.

\section{Patients and methods}

Thirty two patients (18 girls and 14 boys) aged 2-19 years presented with symptoms suggestive of adrenal insufficiency. Fourteen had been irradiated for brain tumours (six medullo-blastomas, three astrocytomas, one optic glioma, one pituitary germ cell, one pineal tumour, one neuro-ectodermal tumour, and one basal ganglia tumour); two had total body irradiation for relapsed non-Hodgkin's lymphoma and acute lymphoblastic leukaemia; 13 had other endocrinopathies (four isolated growth hormone deficiencies, three 

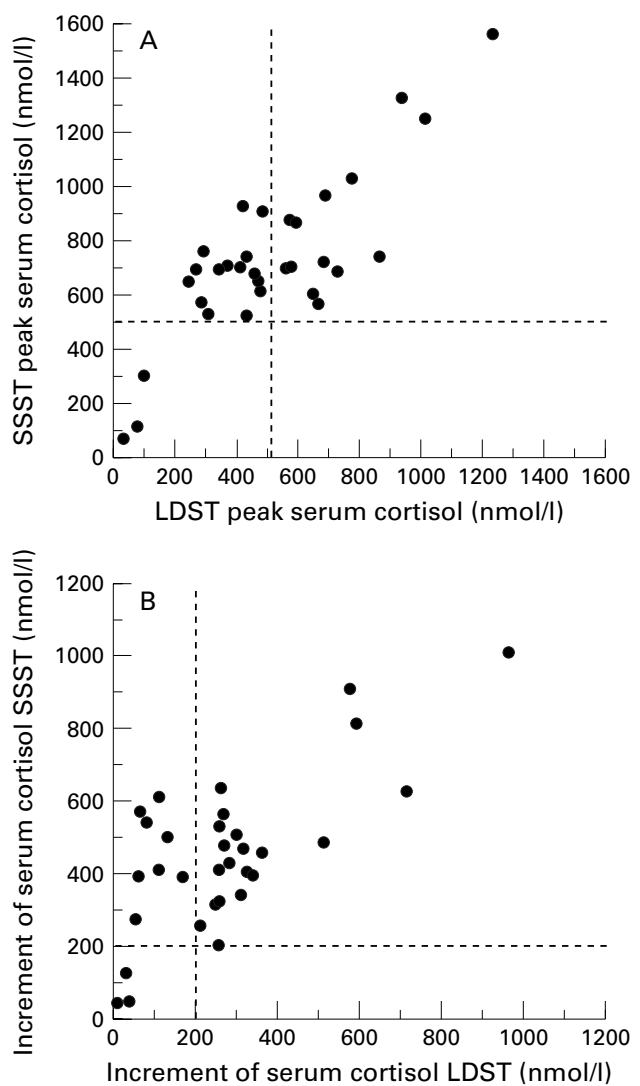

Figure 1 (A) Relation between the peak serum cortisol concentration obtained after the standard short synacthen test (SSST) and the low dose synacthen test (LDST). The cut off values for normal peak cortisol responses (500 nmol/l) to the SSST and LDST are indicated by the dotted lines. (B) Relation between the increment from basal concentrations of serum cortisol obtained after the SSST and the LDST. The cut off values for normal increments of serum cortisol concentrations (200 nmol/l) after the SSST and LDST are indicated by the dotted lines.

panhypopituitarism, one precocious puberty, one transphenoidal surgery for pituitary gigantism, one congenital adrenal hyperplasia, one delayed puberty, one autoimmune thyroiditis, one hypocalcaemia); two had growth failure; and one had histiocytosis with prolonged dexamethasone treatment.

The patients were admitted the night before the study and an indwelling intravenous cannula was inserted. Serum cortisol concentration was estimated between 08:00 and 09:00 hours, before the patient arose from bed.

The LDST was performed at 14:00 hours after a two hour rest following a light lunch at 12:00 hours. A bolus injection of $500 \mathrm{ng} /$ $1.73 \mathrm{~m}^{2}$ of ACTH (1-24) (Synacthen; Ciba Laboratories, Horsham, West Sussex, UK) was given intravenously and sampling took place at $0,10,15,20,25,30,35,40$, and 45 minutes.

The next day, an SSST was performed at 09:00 hours: $250 \mu \mathrm{g} / 1.73 \mathrm{~m}^{2}$ of synacthen was given as an intravenous bolus with sampling at 0,30 , and 60 minutes. The 30 minute peak was studied because it is the value that has been standardised against responses to insulin induced hypoglycaemia.

The study was approved by the local ethics committee.
HORMONE ASSAY

Cortisol was measured using a direct coated tube assay (Euro DPC Ltd, Llanberies, Gwynedd, UK). This assay has a lower limit of detection of $6 \mathrm{nmol} / 1$. The within assay coefficients of variation were $5.7 \%$ and $2.6 \%$ at serum concentrations of $28 \mathrm{nmol} / 1$ and $552 \mathrm{nmol} / 1$, respectively. The between assay coefficients of variation were $9.1 \%$ and $6.8 \%$ at serum concentrations of $95 \mathrm{nmol} / 1$ and $459 \mathrm{nmol} / 1$, respectively.

STATISTICAL ANALYSIS

A normal cortisol response was defined as a peak of $\geqslant 500 \mathrm{nmol} / 1$ and/or an increment from the basal concentration of $\geqslant 200 \mathrm{nmol} / 1 .{ }^{15}{ }^{16}$

The peak and increment following the SSST were plotted against results obtained after the LDST. The sensitivity and specificity of the 08:00 hour serum cortisol concentration compared with the other tests was calculated using standard techniques. ${ }^{18}$

\section{Results}

The relation between the peak serum cortisol concentration obtained after the SSST and LDST is shown in fig $1 \mathrm{~A}$. Figure $1 \mathrm{~B}$ compares the increment from basal values between these two tests. Three patients achieved neither an adequate peak nor increment to either the SSST or LDST. All had a serum 08:00 hour cortisol concentration of $<200 \mathrm{nmol} / \mathrm{l}$. Eight patients had abnormal responses on both criteria to the LDST but had normal responses after the SSST. Three who were offered hydrocortisone replacement treatment have reported amelioration of their symptoms. Twenty one patients had normal responses to both tests. Of these, 14 had an adequate peak and increment after both tests, whereas seven had an inadequate peak only after the LDST but had a normal increment after both tests. These results are summarised in table 1.

The lowest 08:00 hour serum cortisol concentration above which patients achieved normal responses to both the LDST and SSST was $500 \mathrm{nmol} / 1$. At this cut off value, the serum 08:00 hour concentration had a sensitivity of $100 \%$, but specificity was poor at $33 \%$ (table 2).

Twenty four patients had an 08:00 hour serum cortisol concentration of 100$500 \mathrm{nmol} / 1$, including the eight patients who failed the LDST on both criteria and others with a normal response to LDST.

Table 2 Performance of 08:00 hour serum cortisol concentration in relation to incremental rise in serum cortisol concentrations after low dose synacthen test (LDST)

\begin{tabular}{lll}
\hline & \multicolumn{2}{l}{$\begin{array}{l}\text { Increment from basal concentrations } \\
\text { after LDST }\end{array}$} \\
\cline { 2 - 3 } $\begin{array}{l}\text { 08:00 hour serum cortisol } \\
\text { concentration }\end{array}$ & $<200 \mathrm{nmol} / \mathrm{l}$ & $>200 \mathrm{nmol} / \mathrm{l}$ \\
\hline$<500 \mathrm{nmol} / \mathrm{l}$ & 11 & 14 \\
$>500 \mathrm{nmol} / \mathrm{l}$ & 0 & 7 \\
\hline
\end{tabular}




\section{Discussion}

Broadly, there are two groups of patients in which it is necessary to assess adrenal function. The first group comprises those presenting with suggestive symptoms (lethargy, weight loss, anorexia, nausea, vomiting, hyperpigmentation, shock, hypoglycaemia, and electrolyte imbalance). The other group comprises those at risk of developing adrenal insufficiency. This includes patients who have had previous glucocorticoid treatment at supraphysiological doses, cranial irradiation, hypothalamopituitary disease, or pituitary surgery. Although the diagnoses of our cohort are varied, they all presented with symptoms that made adrenal insufficiency part of the differential diagnosis. Twenty one of our patients with suggestive symptoms had normal results to both SSST and LDST, showing how non-specific most of the symptoms are.

The ideal test for diagnosing hypothalamopituitary-adrenal insufficiency needs to be easy to perform, safe, and reliable. The SSST is widely used as a screening test. However, in patients with recent onset hypopituitarism, there is a risk of obtaining false normal results using the SSST because in such patients the adrenal gland will retain its ability to respond to ACTH. ${ }^{9}$ Recently, Soule et al reported failure of the SSST to diagnose unequivocally a 51 year old woman with long standing symptomatic secondary hypoadrenalism. ${ }^{17}$ Graybeal and Fang showed that by the direct measurement of ACTH concentrations, the dose of ACTH used in the SSST far exceeded that produced physiologically in response to insulin induced hypoglycaemia, ${ }^{18}$ which may account for the misleading results that are obtained occasionally. In our patients, the SSST showed a positive bias when compared with the LDST. It has been suggested that increasing the cut off value of peak serum cortisol obtained after the SSST to $600 \mathrm{nmol} / 1$ might improve sensitivity, ${ }^{19}$ but this was not the case in our cohort. The dose of ACTH used in the LDST is 500 times smaller than the standard dose and has been shown to elicit a satisfactory cortisol response in healthy children and adults. ${ }^{12-14}$

The three patients who failed both the SSST and LDST clearly had severe adrenal insufficiency, as supported by a low 08:00 hour serum cortisol concentration. Two of these patients have panhypopituitarism, whereas the third has congenital adrenal hyperplasia. The eight patients who failed the LDST but had normal responses to the SSST probably have mild adrenal insufficiency. Three were treated with hydrocortisone replacement because of the severity of their symptoms and have improved clinically. No patient in our series failed the SSST but passed the LDST. We did not compare the response to the LDST with that obtained after an insulin tolerance test, so it is possible that the LDST may overdiagnose adrenal insufficiency. This is preferable to underdiagnosis, which can occur using the SSST. Rasmussen et al, comparing the LDST (using $1 \mu \mathrm{g}$ of synacthen), SSST, and the insulin tolerance test in 27 patients, showed that the results obtained after the LDST more closely mirrored those obtained after the insulin tolerance test than did those obtained after the SSST. ${ }^{20}$ Brodie et al reported steroid treated asthmatic patients with adrenal insufficiency who had abnormal responses to LDST but normal responses to SSST. ${ }^{14}$ In the insulin tolerance test, hypoglycaemia stimulates the hypothalamus and pituitary gland to release ACTH and this enables assessment of the whole hypothalamo-pituitary-adrenal axis. Plumpton and Besser showed that a peak serum cortisol of $580 \mathrm{nmol} / 1$ after the insulin tolerance test (using a fluorimetric assay) equated to ability to cope with surgical stress. ${ }^{21}$ The insulin tolerance test is considered by most endocrinologists as the gold standard but it is potentially dangerous. Previously documented complications include convulsions, loss of consciousness, and death.

A single estimation of the early morning serum cortisol concentration is easy to perform and reflects peak endogenous secretion. Jones et al found that, at a cut off value of $500 \mathrm{nmol} / \mathrm{l}$, early morning cortisol concentration had a sensitivity of $100 \%$ when compared with the cortisol response to insulin induced hypoglycaemia. ${ }^{3}$ This agrees with our results. However, the specificity at this cut off value was poor. Other authors have shown that an early morning cortisol concentration of $<100 \mathrm{nmol} /$ 1 is indicative of adrenal insufficiency. ${ }^{2}$ In our study, all patients who failed the LDST had 08:00 hour serum cortisol concentrations of $<200 \mathrm{nmol} / \mathrm{l}$. Patients who have early morning serum cortisol concentrations between $100 \mathrm{nmol} / 1$ and $500 \mathrm{nmol} / 1$ need to be investigated using other tests to ascertain their adrenal function status.

Although the timing of peak cortisol measurements after the LDST was variable in our patients, the same conclusion would have been drawn if the sampling time had been limited to $0,10,20$, or 30 minutes.

The LDST is performed in the afternoon when basal cortisol concentrations are low, and this test can be performed as an outpatient procedure.

The LDST detected patients with adrenal insufficiency who had normal responses to SSST and we recommend that it should replace the SSST as the initial screening test in patients in whom adrenal insufficiency is suspected. In patients with borderline results to LDST it may be prudent to perform an insulin tolerance test.

1 Grinspoon SK. Laboratory assessment of adrenal insufficiency. 7 Clin Endocrinol Metab 1994;79:923-30.

2 Hagg E, Asplund K, Lither F. Value of basal cortisol assays in the assessment of pituitary-adrenal insufficiency. Clin in the assessment of pituitar

3 Jones S, Trainer P, Perry L, Wass J, Besser G, Groossman A. An audit of insulin tolerance test in adult subjects in an acute investigation unit over one year. Clin Endocrinol 1994;41:123-8

4 Pavord S, Girach A, Price D, Absalom S, Falconer-Smith J, Howlett T. A retrospective audit of the combined pituitary
function test using insulin stress test TRH and GnRH in a district laboratory. Clin Endocrinol 1992;36:135-9.

5 Watts N, Tindall G. Rapid assessment of corticotrophin reserve after pituitary surgery. $¥ A M A$ 1988;259:708-11.

6 reserve after pituitary surgery. $\mathcal{F}$. HA 1988;259:708-11. Shah A, Stanhope R, Mathews D. Hazards of pharmacologi-
cal tests of growth hormone secretion in childhood. BMF 1992;304:173-4. 
7 Stewart PM, Corrie J, Seckl JR, Edwards CPW, Paadfield FL. A rational approach for assessing the hypothalamopituitary-adrenal axis. Lancet 1988;i:249-51.

8 Kehlet H, Blichert-Toft M, Lindholm J, Rasmussen P. Short ACTH test in assessing hypothalamic-pituitaryadrenocortical function. BMF 1976;i:249-51.

9 Borst GC, Michenfelder HJ, O'Brian JT. Discordant cortisol response to exogenous ACTH and insulin induced hypoglycaemia in patients with pituitary disease. $N$ Engl $\mathcal{F}$ Med 1982;302:1462-4.

10 Cunningham SK, Moore A, Mckenna J. Normal cortisol response to corticotrophin in patients with secondary adrenal failure. Arch Intern Med 1983;143:2276-9.

11 Crowley S, Hindmarsh PC, Honour JW, Brook CGD. The use of low doses of ACTH in the investigation of adrenal function in man. F Endocrinol 1993;136:167-72.

12 Crowley S, Hindmarsh PC, Honour JW, Brook CGD Reproducibility of cortisol response to stimulation with a low dose of ACTH (1-24): the effect of basal cortisol levels and comparison of low-dose with high-dose secretory dynamics. F Endocrinol 1993;136:167-72

13 Daidoh H, Morita T, Mune T, et al. Responses of plasma adrenocortical steroids to low dose ACTH in normal subjects. Clin Endocrinol 1995;43:311-15.
14 Brodie J, Soferman R, Kivity S, Golander A, Dickstein G, Spirer Z. Low dose adrenocorticotropin test reveals impaired adrenal function in patients taking inhaled

15 Corticosteroids. F Clin Endocrinol Metab 1995;80:1243-5. Wood JB, James VHT, Frankland AW, Landon J. A

16 Musa BU, Dowling JT. Rapid intravenous administration of corticotrophin as a test of adrenocortical insufficiency. FAMA 1967;201:633-5.

17 Soule G, Fahie-Wilson M, Tomlinson S. Failure of the short ACTH test to unequivocally diagnose long-standing symp44:137-40.

18 Graybeal ML, Fang VS. Physiological dosing of exogenous ACTH. Acta Endorinologica 1985;108:401-6.

19 Hurel SJ, Thompson CJ, Watson MJ, Harries PH, Baylis $\mathrm{PH}$, Kendall-Taylor P. The short synacthen and insulin stress tests in the assessment of the hypothalamicpituitary-adrenal axis. Clin Endocrinol 1996;44:141-6.

20 Rasmussen S, Olsson T, Hagg E. A low dose ACTH test to assess the function of the hypothalamic-pituitary-adrenal assess the function of the hypothalami
axis. Clin Endocrinol 1996;44:151-6.

21 Plumpton F, Besser G. The adrenocortical response to surgery and insulin induced hypoglycaemia in corticosteroid treated and normal subjects. Br F Surg 1966;56:216-19. 